\author{
Andrzej Dietrich \\ Instytut Nafty i Gazu - Państwowy Instytut Badawczy
}

\title{
Obliczenia w chmurze i obliczenia gridowe
}

\begin{abstract}
Celem artykułu jest przegląd nowych technologii informatycznych, a w szczególności tych, które mają wpływ na obliczenia o dużej złożoności i wymagające użycia sporych mocy obliczeniowych. Zaprezentowano możliwości obliczeń w chmurze i obliczeń gridowych. Przedstawiono przykłady gridów i chmur obliczeniowych. Wskazano na korzyści płynące dla nauki i przemysłu ze stosowania nowych technologii obliczeń.
\end{abstract}

Słowa kluczowe: wirtualizacja, obliczenia rozproszone, obliczenia równoległe, obliczenia w chmurze, klastry obliczeniowe, obliczenia gridowe.

\section{Cloud and grid computing}

The objective of this paper is to give an overview of new information technologies, particular those which influence high complex computing and require the use of considerable computing power. This article presents possibilities of cloud and grid computing. The grid and cloud computing applications and implementations are presented. It points out the benefits that science and industry have gained, due to the application of new computing technologies.

Key words: virtualization, distribution computing, parallel computing, cloud computing, cluster computing, grid computing.

\section{Wprowadzenie}

Problemy stawiane przed współczesną nauką są coraz bardziej złożone. Niektórych z nich nie udałoby się rozwiązać inaczej, niż stosując modelowanie matematyczne i symulacje komputerowe. Zdarza się, że potwierdzają one wykryte wcześniej, na drodze teoretycznych rozważań, hipotezy. Przykładem może być potwierdzenie istnienia cząstki elementarnej Higgsa w eksperymencie na Wielkim Zderzaczu Hadronów. Złożone problemy dużej skali, połączone z przetwarzaniem olbrzymich ilości danych, wymagają coraz więk- szych mocy obliczeniowych. Możliwości związane z rozwojem Internetu spowodowały gwałtowny rozwój nowych technologii obliczeniowych. W artykule dokonano ich przeglądu. Przedstawiono przykłady realizacji najnowszych osiągnięć w dziedzinie obliczeń, wymagających dużych mocy obliczeniowych - zarówno na świecie, jak i w Polsce. Wskazano na korzyści płynące ze stosowania tych technologii, zarówno z punktu widzenia badań naukowych, jak i przemysłowych zastosowań, np. w przemyśle naftowo-gazowniczym.

\section{Technologie informatyczne - przegląd}

W ostatnich latach powstały i dynamicznie rozwijają się nowe technologie informatyczne wspomagające między innymi badania naukowe i prowadzenie obliczeń dużej skali w zakresie modelowania matematycznego i symulacji komputerowych. Technologie takie jak: wirtualizacja (ang. virtualization), chmury obliczeniowe (ang. cloud computing), obliczenia rozproszone i równoległe (ang. distribution and parallel computing), klastry obliczeniowe (ang. cluster compu- ting) oraz gridy obliczeniowe (ang. grid computing) i gridy dziedzinowe (ang. domain grids) pozwalają na wykonywanie zadań obliczeniowych, wcześniej niemożliwych do realizacji. Wymienione wyżej metody rozwinęły się w oparciu o Internet i technologie z nim związane, takie jak WWW, a zwłaszcza Web 2.0.

Na rysunku 1 przedstawiono w postaci piramidy technologie informatyczne, które kształtują dzisiejsze możliwości ob- 
liczeniowe. Na samym szczycie znajdują się gridy, a dokładniej obliczenia gridowe i związane z nimi gridy dziedzinowe.

Poniżej przedstawiono, w celu przypomnienia i uporządkowania, kilka definicji pojęć występujących w piramidzie technologii informatycznych. Należy przy tym zaznaczyć, że część z tych definicji nie jest powszechnie akceptowana. Niektóre $\mathrm{z}$ technologii nadal są rozwijane $\mathrm{i}$ ich terminologia nie została jeszcze ostatecznie ustalona. Często zatem zamiast definicji grida obliczeniowego podaje się przykład takiego rozwiązania. Spory, np. dotyczące tego, co jest gridem, a co nim nie jest, nie są rzadkością. Oto kilka prób definicji:

Informatyka to dyscyplina naukowa zajmująca się przetwarzaniem informacji z użyciem komputerów - obejmuje teorie informatyczne, budowanie systemów informatycznych (w tym programowanie), budowę i działanie sprzętu komputerowego, zastosowania metod informatycznych w różnych dziedzinach działalności ludzkiej. Informatyka posługuje się językiem i metodami matematyki, logiki matematycznej i specyficznych dziedzin, takich jak: teoria języków formalnych i automatów abstrakcyjnych, teoria algorytmów, teoria obsługi masowej - tworzą one swój własny język i metody [13].

Internet to ogólnoświatowa sieć komputerowa łącząca lokalne sieci, korzystająca z pakietowego protokołu TCP/IP, mająca jednolite zasady adresowania i nazywania węzłów (komputerów włączonych do sieci) oraz protokoły udostępniania informacji [13].

WWW (ang. World Wide Web) - ,wszechświatowa pajęczyna", to najpopularniejsza usługa udostępniania informacji w sieci Internet lub intranet, z wykorzystaniem protokołu komunikacyjnego HTTP (ang. Hyper Text Transfer Protocol)

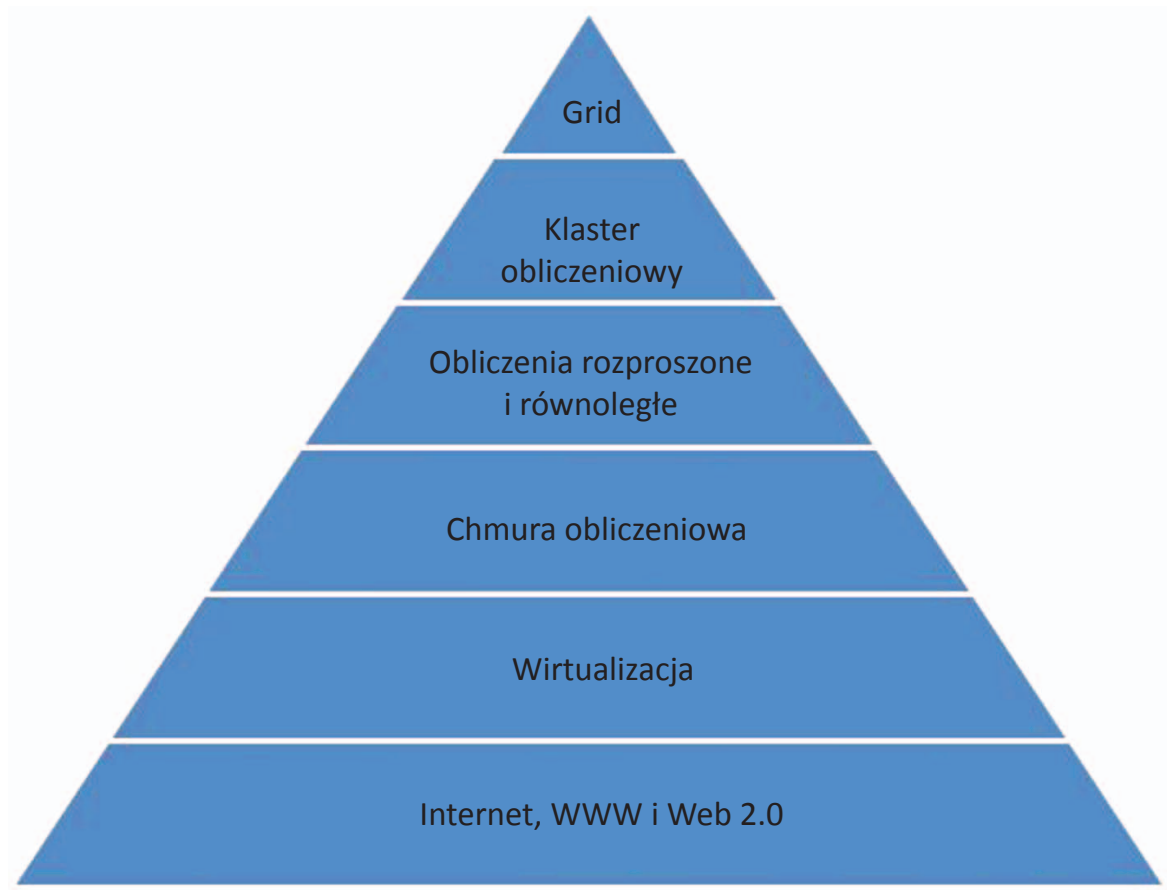

Rys. 1. Piramida technologii informatycznych i języka HTML. Do wyszukiwania i przeglądania informacji w systemie (serwisie) WWW służą specjalne programy, tzw. przeglądarki WWW [13].

Web 2.0 - potoczne określenie serwisów internetowych powstałych po roku 2001. Cechą charakterystyczną tej technologii jest duża interakcja pomiędzy użytkownikami, dlatego serwisy Web 2.0 umownie nazywa sie .,dynamicznymi” - dla odróżnienia od „statycznych" serwisów tradycyjnych, które nie umożliwiają interakcji. Ważną cechą jest również łatwość i efektywność tych serwisów, połączona z jakością otrzymania „usługi na żądanie” (ang. service on demand). Obliczenia w chmurze wykorzystują technologię Web 2.0 [12].

Wirtualizacja (ang. virtualization) - pozwala na jednoczesne uruchomienie wielu systemów operacyjnych na tej samej platformie sprzętowej i systemowej, przy maksymalnej możliwej wydajności. Technologie wirtualizacji umożliwiają podział infrastruktury informatycznej (urządzeń, zasobów, sieci, a nawet technologii) na części. Na przykład wirtualizację serwerów definiuje się jako dzielenie, inaczej partycjonowanie, fizycznego serwera na dużo mniejsze serwery wirtualne. Każdej z wirtualnych maszyn pozwala się pracować na macierzystym systemie operacyjnym, jak również mogą być one wyłączane oraz uruchamiane niezależnie od siebie. Na rynku działają firmy oferujące narzędzia programistyczne do wirtualizacji. Wśród nich najbardziej znane to: Vmware, Microsoft Hyper-V i Citrix XenServer [12]. Technologie wirtualizacji są podstawą obliczeń w chmurze.

Chmura obliczeniowa (ang. cloud computing) - to model przetwarzania danych oparty na użytkowaniu usług dostarczonych przez usługodawcę (wewnętrzny dział lub zewnętrzna organizacja). Funkcjonalność jest tu rozumiana jako usługa oferowana przez dane oprogramowanie (oraz konieczną infrastrukturę sprzętową). Oznacza to eliminację konieczności zakupu licencji czy potrzeby instalowania i administracji oprogramowania. Technologia ta jest nadal rozwijana. W osobnym rozdziale omówiono przykład chmury obliczeniowej zbudowanej w Instytucie Fizyki Jądrowej PAN w Krakowie [5].

Obliczenia rozproszone (ang. distributed computing) - to obliczenia umożliwiające współdzielenie zasobów obliczeniowych, często rozproszonych geograficznie. Zadanie obliczeniowe poddane zostaje dekompozycji, np. na programy, procesy lub procesory. Przykładem są obliczenia na klastrach komputerowych, w szczególności heterogenicznych [12]. 
Obliczenia równoległe (ang. parallel computing) - to taka forma obliczeń, w której sporo instrukcji jest wykonywanych jednocześnie. Aby rozwiązać dany problem, wykorzystuje się tu wiele jednostek obliczeniowych w tym samym czasie [12].

Klaster obliczeniowy (ang. cluster computing) - to grupa połączonych jednostek komputerowych, które współpracują ze sobą w celu udostępnienia zintegrowanego środowiska pracy. Komputery wchodzące w skład klastra (będące członkami klastra) nazywamy węzłami (ang. node) [12].

Grid obliczeniowy (ang. grid computing) - to infrastruktura sprzętowa i programowa, która w sposób niezawodny, spójny, rozproszony i relatywnie tani zapewnia dostęp do zasobów obliczeniowych. Grid zapewnia ściśle kontrolowane współdzielenie zasobów. Precyzyjnie zdefiniowane reguły współdzielenia (kto, pod jakimi warunkami) określają zbiór jednostek i instytucji, które tworzą wirtualną organizację. Przy czym współdzielenie nie dotyczy prostej wymiany plików, lecz raczej bezpośredniego dostępu do komputerów, oprogramowania, danych i zasobów. Wspólna infrastruktura obliczeniowa i wymiana jest możliwa dzięki standardowym protokołom [10]. Technologia gridowa to rozwinięcie idei klastra obliczeniowego. Jest ona nadal rozwijana, znajdując nowe obszary zastosowań. Jako przykład można wskazać popularność i dynamiczny rozwój tzw. gridów dziedzinowych. Gridy podobnie jak technologie webowe ukrywają złożoność i analogicznie do klastrów oraz obliczeń rozproszonych łączą zasoby obliczeniowe. Gridy odmiennie od klastrów, które wymagają fizycznej bliskości i jednorodnego środowiska, mogą być geograficznie rozproszone i niejednorodne. Gridy podobnie jak techniki wirtualizacji wspierają wirtualizację.

Główne korzyści płynące z obliczeń gridowych to możliwości:

- użycia zasobów obliczeniowych rozproszonych po całym świecie, a zatem dostęp do większych mocy obliczeniowych, łatwiejszy i lepszy dostęp do danych,

- prowadzenia obliczeń o wysokim poziomie złożoności i skali,

- lepszej współpracy zespołów badawczych i wirtualnych organizacji - grup organizacji wykorzystujących grid do współdzielenia zasobów [10].

W dalszej części artykułu omówione zostały przykładowe realizacje gridów obliczeniowych.

\section{Chmura obliczeniowa - przykład}

Opracowany w Instytucie Fizyki Jądrowej PAN im. Henryka Niewodniczańskiego system obliczeń w chmurze CC1 jest dobrym przykładem wykorzystania technik wirtualizacji i technologii chmury obliczeniowej (ang. cloud computing) [5]. System ten oferuje kompletne rozwiązanie przekształcające dostępną infrastrukturę komputerową w prywatną chmurę obliczeniową. System CC1 umożliwia organizację zasobów komputerowych w formie prywatnej chmury obliczeniowej, typu infrastruktura, jako usługi (ang. IaaS - Infrastructure as a Service) opartej na wirtualizacji sprzętowej. Główną funkcją systemu jest szybkie dostarczanie na życzenie:

- maszyny wirtualnej (VM) wraz z wymaganym systemem operacyjnym,

- przestrzeni dyskowej,

- infrastruktury sieciowej.

Z punktu widzenia użytkownika maszyna wirtualna może być wykorzystywana jak fizyczny komputer zlokalizowany w odległej serwerowni. Zasobami obliczeniowymi zarządza

Tablica 1 . Cechy systemu CC1

\begin{tabular}{|c|l|l|}
\hline Lp. & \multicolumn{1}{|c|}{ Cecha systemu CC1 } & \multicolumn{1}{c|}{ Opis } \\
\hline 1. & Monitoring & Podgląd obciążenia maszyn wirtualnych i śledzenie ich historii \\
\hline 2. & System rozliczeniowy & Pomiar wykorzystania zasobów przez poszczególnych użytkowników \\
\hline 3. & Kontrola przydziału zasobów & Limity użycia zasobów (CPU, RAM, przestrzeń dyskowa) przez użytkowników \\
\hline 4. & Rozproszona struktura & Centralny kontroler chmury, zarządzający odległymi klastrami obliczeniowymi \\
\hline 5. & Elastyczne dopinanie IP & Elastyczne dołączanie publicznych adresów IP do maszyn wirtualnych \\
\hline 6. & Wirtualne klastry & Klastry maszyn wirtualnych skonfigurowane do pracy w systemie kolejkowym \\
\hline 7. & Wirtualne dyski & Gromadzenie danych na dynamicznie przyłączanych dyskach USB \\
\hline 8. & Obrazy systemu & Obrazy z systemem operacyjnym \\
\hline 9. & Grupy użytkowników & Współdzielenie zasobów bez asysty administratora systemu \\
\hline 10. & Zaawansowana kontekstualizacja & Komunikacja z systemem operacyjnym maszyny z przeglądarki internetowej \\
\hline 11. & Interfejs EC2 & Dostęp do zasobów za pośrednictwem popularnych zewnętrznych narzędzi \\
\hline 12 & Interfejs przeglądarkowy & Błyskawiczny dostęp do zasobów wirtualnych z przeglądarki internetowej \\
\hline
\end{tabular}


się za pomocą dedykowanego intuicyjnego interfejsu WWW, a ich rezerwacja przeprowadzana jest w sposób samoobsługowy - bez udziału administratora systemu - co jest jedną z kluczowych cech technologii obliczeń w chmurze. Wirtualizacja umożliwia wspótistnienie maszyn o różnych systemach operacyjnych na jednym fizycznym komputerze. Zasoby są dostępne po krótkim okresie, bez konieczności wcze- śniejszej deklaracji ich wielkości i czasu wykorzystania. Po wykonaniu zadań zasoby mogą być zwolnione do wykorzystania przez innych użytkowników. Ten elastyczny sposób dostępu pozwala wielokrotnie zwiększyć efektywność wykorzystania infrastruktury obliczeniowej [5].

W tablicy 1 zestawiono najważniejsze cechy systemu CC1 [5].

\section{Przykłady rozwiązań gridowych}

Gridy obliczeniowe tworzy się po to, aby umożliwić zainteresowanym organizacjom wzajemną wymianę mocy obliczeniowych i innych zasobów infrastruktury informatycznej (np. pamięci masowe). Technologia obliczeń gridowych pozwala rozwiązywać bardzo złożone problemy dużej skali w większym stopniu niż superkomputery i klastry obliczeniowe. Do tworzenia gridu potrzebne są technologie programowe. Najbardziej znaną jest Globus Toolkit. Oto kilka przykładów gridów obliczeniowych:

1. TeraGrid - grid zbudowany na potrzeby wspólnych i otwartych badań naukowych, łączący główne ośrodki akademickie w USA (www.teragrid.org);

2. Information Power Grid - grid obliczeniowy NASA charakteryzujący się wysoką wydajnością (www.ipg.nasa.gov);

3. European Union Data Grid - grid do zastosowań w fizyce, bioinformatyce i naukach środowiskowych;

4. World LHC Computing Grid (WLCG) - grid obliczeniowy do prowadzenia eksperymentów naukowych w Ośrodku Naukowo-Badawczym, Europejskiej Organizacji Badań Jądrowych - CERN, w Genewie (www.wlcg. web.cern.ch). Jest to największy w świecie grid obliczeniowy. Jego głównym celem i zarazem misją jest udostępnienie olbrzymich zasobów komputerowych do gromadzenia, dystrybucji i analizy danych generowanych przez Wielki Zderzacz Hadronów (ang. Large Hadron Collider). Dane te są dostępne wszystkim uczestnikom projektu, na jednakowych zasadach, niezależnie od ich fizycznej lokalizacji. Grid ten jest wspierany przez inne przedsięwzięcia gridowe, takie jak Europejska Inicjatywa Gridowa (ang. European Grid Initiative) i Grid Otwartej Nauki (ang. Open Science Grid) z USA oraz wiele innych regionalnych centrów gridowych - w tym krakowski Cyfronet AGH. Koordynatorem WLCG jest CERN. W przedsięwzięciu tym uczestniczą 42 kraje, 170 centrów komputerowych. Każdego dnia wykonywane są 2 miliony zadań obliczeniowych. Obliczenia przeprowadzone z użyciem tego gridu pozwoliły na odkrycie w roku 2012 nowej cząstki elementarnej - ang. Bozon Higgsa, której istnienie przewidział w swoim modelu Peter Higgs, laureat Nagrody Nobla w 2013 roku.
5. PLGrid - to pierwszy polski grid obliczeniowy. W styczniu 2007 roku w Polsce zostało utworzone konsorcjum PL-Grid. W jego skład weszło pięć dużych Centrów Komputerowych Dużej Mocy Obliczeniowej z Gdańska, Krakowa, Poznania, Warszawy i Wrocławia. Zaczęto realizację szeregu projektów związanych z technologiami gridowymi i chmurowymi. W ramach projektu PL-Grid (2009-2012), koordynowanego przez ACK Cyfronet AGH w Krakowie, zbudowano niezawodną i nowoczesną infrastrukturę obliczeniową dla nauki, opartą na klastrach komputerów zlokalizowanych w pięciu największych centrach komputerowych w Polsce [2-4]. Rozbudowano sprzęt komputerowy i wdrożono nowe oprogramowanie. Udostępniono wielką moc obliczeniową, a także duże zasoby pamięci masowych oraz dedykowane narzędzia programistyczne umożliwiające tworzenie zaawansowanych aplikacji naukowych wraz z wizualizacją otrzymanych wyników. Każda osoba prowadząca badania naukowe może być użytkownikiem tej zaawansowanej i nowoczesnej infrastruktury obliczeniowej. Dostęp do wielkich mocy obliczeniowych, ogromnych zasobów pamięci oraz zaawansowanych usług jest nieodpłatny. Jedyny warunek to założenie konta przez Portal PL-Grid. W ramach kolejnego projektu PLGrid Plus (2011-2014) opracowano i wdrożono dedykowane środowiska informatyczne (usługi i oprogramowanie), zwane gridami dziedzinowymi, dla potrzeb 13 różnych grup naukowców. Kolejne, 14. gridy dziedzinowe powstały w ramach projektu PLGrid NG (2014-2015). Przedstawiciele takich dyscyplin jak: chemia, biologia, fizyka, astrofizyka, akustyka, energetyka, geoinformatyka, ekologia, hydrologia, meteorologia czy nanotechnologia mogą korzystać z gridów dziedzinowych. Ich pełny wykaz znajduje się na stronach internetowych projektu PLGrid [11]. Lista ta nie jest zamknięta, a nowe gridy dziedzinowe są nadal tworzone. Rozbudowa infrastruktury obliczeniowej w kierunku rozwiązań dziedzinowych pozwoli na bardziej efektywne prowadzenie badań naukowych. W ramach projektu PLGrid CORE rozbudowywana jest infrastruktura gridowa, o technologie obliczeń w chmurze i analizę dużych i rozproszonych zbiorów danych. Wprowadzenie chmu- 
ry obliczeniowej umożliwia większą elastyczność badań, ponieważ użytkownik może dostosować przydzielone mu maszyny wirtualne (komputery) do swoich specyficznych potrzeb. Chmura obliczeniowa pozwala na łatwe zbudowanie i uruchomienie środowiska testowego. Użytkownik może włączać swoje aplikacje w różnych systemach operacyjnych (Windows, Linux). Otrzymuje on jedną lub kilka maszyn wirtualnych z pełnymi prawami dostępu na poziomie administratora. W celu zapewnienia odpowiedniego bezpieczeństwa, wszystkie maszyny wirtualne pracują w dedykowanej sieci lokalnej. Na potrzeby w szczególności nowych użytkowników PLGrid stworzony został Kata$\log$ Aplikacji prezentujący pełną i aktualną ofertę oprogramowania, z podziałem na kategorie, zastosowania i dziedziny naukowe [8]. Dzięki infrastrukturze PLGrid możliwe jest również skorzystanie z narzędzi pracy zespołowej, wspierających organizację, planowanie i zarządzanie projektami lub zespołami badawczymi.
6. Grid obliczeniowy - 3DGeo - do interpretacji i wizualizacji danych sejsmicznych. Zbudowany został przez amerykańską firmę 3DGeo, wytwarzającą zaawansowane oprogramowanie dla przemysłu naftowo-gazowniczego [1]. Skomplikowane obliczenia związane z modelowaniem sejsmicznym i przetwarzaniem podpowierzchniowych obrazów 3D, w połączeniu z olbrzymią ilością danych, wymagają bardzo dużych zasobów obliczeniowych. Wprowadzenie obliczeń gridowych pozwoliło na większy i bardziej elastyczny dostęp do zasobów - danych i mocy obliczeniowych komputerów, oraz skróciło znacząco czas obliczeń. Szacuje się, że czas od pozyskania danych pomiarowych do podjęcia decyzji o wykonaniu wiercenia zostanie skrócony czterokrotnie. Możliwe jest to nie tylko dzięki zwiększonym mocom obliczeniowym, ale także dzięki możliwości przesyłania przez Internet olbrzymich ilości danych (setki terabajtów), przy wykorzystaniu usługi Grid FTP [1].

\section{Podsumowanie}

W wyniku rozwoju nowych technik i technologii informatycznych nauka i przemysł uzyskują dostęp do nowatorskich, bardziej wydajnych zasobów obliczeniowych (sprzęt komputerowy i oprogramowanie). Łatwiejszy staje się dostęp do większych mocy obliczeniowych oraz do baz danych - często o wielkich rozmiarach. Złożone obliczenia można będzie przeprowadzić w krótszym czasie. Technologia obliczeń gridowych czyni współpracę grup organizacji i zespołów badawczych wydajniejszą. Współdzielenie zasobów obliczeniowych przyczynia się do lepszego ich wykorzystania.

Obliczenia z dziedziny modelowania sejsmicznego [7, 9], jak i symulacje złożowe [6] to przykłady, które mogłyby być zrealizowane przy pomocy obliczeń gridowych, stając się przyczynkiem do zbudowania dwóch nowych gridów dziedzinowych w ramach Polskiej Infrastruktury Gridowej [11].

W jednostkach badawczych tworzone są często zespoły skupiające specjalistów z różnych dziedzin. W takich zespołach wykorzystanie mocy obliczeniowych jest zazwyczaj na niskim poziomie. Różnice w wymaganiach sprzętowych i oprogramowaniu powodują, że każdy zespół badawczy prowadzi obliczenia na „swoim” komputerze, zlokalizowanym zazwyczaj w pobliżu miejsca pracy lub rzadziej w serwerowni. Techniki wirtualizacji i obliczeń w chmurze pozwalają na przekształcenie tej niejednorodnej i rozproszonej infrastruktury obliczeniowej w jeden uniwersalny klaster obliczeniowy, zapewniający wspólistnienie na nim wielu różnych systemów operacyjnych [5].

W przypadku przemysłu instalacja systemu prywatnej chmury w firmie przynosi realne korzyści finansowe. Przekształcona w chmurę obliczeniową, złożona i niejednorodna infrastruktura informatyczna jest bardziej wydajna i łatwiej zarządzana. Zmniejszają się także koszty związane z jej utrzymaniem i administrowaniem. Wyższa wydajność i zmniejszające się nakłady na utrzymanie całej infrastruktury powodują zwiększenie konkurencyjności firmy [5].

Technologie obliczeń gridowych i obliczeń w chmurze są nadal rozwijane, a kluczową sprawą stają się problemy bezpieczeństwa danych.

Prosimy cytować jako: Nafta-Gaz 2016, nr 12, s. 1150-1155, DOI: 10.18668/NG.2016.12.20

Artykuł nadesłano do Redakcji 21.11.2016 r. Zatwierdzono do druku 2.12.2016 r.

Artykuł powstał na podstawie pracy statutowej pt. Rozwój i eksploatacja sieci komputerowych w INiG-PIB w 2016 roku - praca INiG - PIB na zlecenie MNiSW; nr zlecenia: 70/SP/16, nr archiwalny: DK-5100/83/2016.

\section{Literatura}

[1] Bevc D., Zarantonello S.E., Kaushik N., Musat I.: Grid computing for energy exploration; http://fusiongeo.com/publications/k3d/GGF14 3DGeo.pdf (dostęp: 14.11.2016).

[2] Bubak M., Kitowski J., Wiatr K.: eScience on Distributed
Computing Infrastructure. Achievements of PLGrid Plus Domain - Specific Services and Tools. Springer LNCS 2014, vol. 8500 .

[3] Bubak M., Szepieniec T., Wiatr K.: Building a National Di- 
stributed e-Infrastructure - PLGrid, Scientific and Technical Achievements. Springer LNCS 2012, vol. 7136.

[4] Bubak M., Turała M., Wiatr K.: PLGrid Infrtastructure: a Tool for Open Science. Proceedings of CGW Workshop 2016.

[5] Cracow cloud one - Prywatna chmura Obliczeniowa; http:// cc1.ifj.edu.pl/ (dostęp: 14.11.2016).

[6] Gołąbek A., Szott W.: Numeryczne modelowanie zjawiska dyspersji fizycznej-modyfikacja petnowymiarowego symulatora złożowego. Nafta-Gaz 2016, nr 7, s. 528-533, DOI: 10.18668/NG.2016.07.05.

[7] Jędrzejowska-Tyczkowska H.: Mikrosejsmika, sejsmika, sejsmologia - wspólne korzenie, różne cele, zintegrowane dziatania. Nafta-Gaz 2016, nr 7, s. 487-501, DOI: 10.18668/ NG.2016.07.01.

[8] Katalog Aplikacji i Usług; www.apps.pl.grid.pl (dostęp: 7.11.2016)

[9] Kostecki A., Żuławiński K.: Modeling and seismic migration in anisotropic media as a function of azimuthal angle-HTI ( $\Psi)$. Nafta-Gaz 2016, nr 9, s. 679-690, DOI: 10.18668/ NG.2016.09.01.
[10] Mincer-Daszkiewicz J.: Gridy - Systemy rozproszone; http:// students.mimuw.edu.pl/SR-MSUI/10-grid/gridy.pdf (dostęp: 17.11.2016).

[11] Polska Infrastruktura Gridowa; www.plgrid.pl (dostęp: 7.11.2016).

[12] Strona internetowa: https://pl.wikipedia.org/wiki/Web 2.0 (dostęp: 17.11.2016).

[13] Strona internetowa: www.encyklopedia.pwn.pl (dostęp: 17.11.2016)

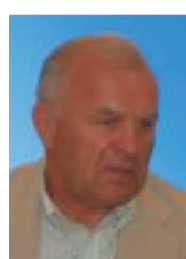

Mgr Andrzej DIETRICH

Kierownik w Zakładzie Informatyki

Instytut Nafty i Gazu - Państwowy Instytut Badawczy

ul. Lubicz 25 A

31-503 Kraków

E-mail: andrzej.dietrich@inig.pl

\section{SRODKI SMAROWE 2017}

KRYNICA ZDRÓJ, 10-12 MAJA 2017 R.

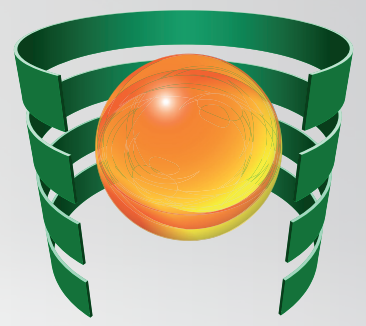

\section{ZAPRASZAMY}

WWW.SRODKISMAROWE2017.INIG.PL

- producentów środków smarowych, olejów bazowych, dodatków do olejów, smarów i cieczy technologicznych

- dystrybutorów komponentów do środków smarowych

- pracowników działów B+R

- kadre zarządzającą gospodarką smarową

- przedstawicieli uczelni i instytutów badawczych

- producentów i dostawców sprzętu laboratoryjnego

- użytkowników środków smarowych

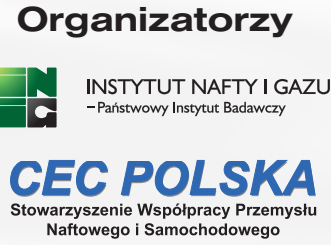

Patroni medialni

Nafta-Gaz

przelingsl chemicany

(1D) UTRZYMANIE

\section{REJESTRACJA UCZESTNIKÓW}

Joanna Oleksik

Tel. 126177495

e-mail: srodkismarowe@inig.pl 